\title{
A FORMAÇÃO POLÍTICA DE TRABALHADORES PRECARIZADOS NO MST E NO MTST
}

\author{
THE POLITICAL TRAINING OF PRECARIZED WORKERS IN THE MST AND MTST
}

\author{
Renan Dias Oliveira ${ }^{1}$
}

Centro Universitário Fundação Santo André, Faculdade de Ciências Econômicas e Administrativas, Brasil, renandoliveira@yahoo.com.br

ARTICLE INFO

Article history:

Received 2018-09-10

Accepted 2019-06-02

Available online 2019-02-07
Palavras-chave: Formação. Política. Trabalhadores. Precarização. MST. MTST

Keywords: Formation. Policy. Workers. Precariousness. MST. MTST.

RESUMO. O tema deste artigo se fundamenta em dois eixos principais: o primeiro procura analisar, do ponto de vista da Sociologia do Trabalho, como o Movimento dos Trabalhadores Rurais Sem-Terra (MST) e o Movimento dos Trabalhadores Sem-Teto (MTST) têm atuado na incorporação de grupos precarizados de trabalhadores rurais e urbanos em suas fileiras de atuação social e política. $O$ segundo procura analisar como os "setores de formação" dos dois movimentos atuam nessa dinâmica de absorção de trabalhadores e na consequente formação política desses mesmos trabalhadores, que irão compor as fileiras dos dois movimentos sociais de forma orgânica, como militantes. Por fim, será feita uma comparação entre as dinâmicas dos dois movimentos, a fim de melhor compreender o caminho percorrido por trabalhadores precarizados, que se tornam atores políticos no interior dos dois maiores movimentos sociais do país. Considera-se importante resgatar trabalhos de pesquisa realizados sobre a formação política em movimentos sociais, mas dando ênfase ao protagonismo político de setores de trabalhadores precarizados nesses dois movimentos.

ABSTRACT. The theme of this article is based on two main axes: the first seeks to analyze, from the point of view of Sociology of Work, such as the Landless Rural Workers Movement (MST) and the Movement of the Homeless Workers (MTST) in the incorporation of precarious groups of rural and urban workers in their ranks of social and political activity. The second seeks to analyze how the "training sectors" of the two movements act in this dynamics of absorption of workers and in the consequent political formation of these same workers, who will form the ranks of the two social movements organically as militants. Finally, a comparison will be made between the dynamics of the two movements in order to better understand the path taken by precarious workers, who become political actors within the two largest social movements in the country. It is considered important to rescue research work carried out on political formation in social movements, but emphasizing the political protagonism of sectors of workers precarized in these two movements. 


\section{INTRODUÇÃO}

A temática da precarização do trabalho no campo não é recente na bibliografia sociológica. A formação estrutural desigual da propriedade fundiária no Brasil e o avanço do capitalismo na zona rural nas últimas décadas criaram um ambiente de trabalho cada vez mais precarizado e carente de direitos sociais. As transformações sociais no meio rural têm se mostrado socialmente excludentes nas últimas décadas, relacionadas a um avanço tecnológico cada vez maior na produção e à precarização do emprego nas relações de trabalho, caracterizadas pelo autoritarismo e pela informalidade. No início da década de 1980 o mercado de trabalho no meio rural sofreu profundas alterações.

Como reflexo do chamado "milagre econômico brasileiro" (1967-1972), a produção rural se viu cada vez mais refém do capitalismo urbano brasileiro. A produção no campo, principalmente a agricultura, assiste também a um crescimento da produtividade e a uma alta especialização do trabalho. E assim como o crescimento industrial, que puxou o "milagre econômico", o crescimento econômico no campo não significou mudanças positivas para os trabalhadores rurais. Destarte conquistas pontuais, a propriedade da terra continuou extremamente concentrada e os direitos sociais avançaram pouco (SILVA, 2007).

Segundo Schlindwein (2011), a Constituição de 1988 pode ser considerada um marco na história da luta por direitos dos trabalhadores rurais no Brasil. Principalmente as conquistas no acesso aos benefícios previdenciários foram frutos de intensa mobilização social. Mas Sant'Ana (2014, p.5) aponta que o modelo agrário monocultor e exportador remonta aos projetos de "modernização do campo" capitaneados pela ditadura civil-militar brasileira (1964-1985) no final dos anos 1970 e início dos anos 1980. Já nesse período a resistência a esse modelo começa também a se articular. Em janeiro de 1984 realiza-se na cidade de Cascavel, estado do Paraná, um grande encontro de trabalhadores rurais, no qual se decide pela construção do Movimento dos Trabalhadores Rurais Sem-Terra, o MST. Em janeiro de 1985 realiza-se na mesma cidade o 1ํ Congresso Nacional do MST. O movimento viria a se constituir como o maior movimento social do país nos anos seguintes e teria um papel decisivo na incorporação de trabalhadores rurais precarizados e na formação política desse contingente, do qual grande parte viria a se tornar militante política ativa do movimento. 


\section{FUNDAMENTAÇÃO}

Hoje o MST conta com onze setores em sua estrutura de organização, sendo um deles de "Educação" e outro de "Formação". O setor de "Educação", que atua constantemente nos acampamentos e assentamentos, abarca uma perspectiva ampla, que envolve desde as necessidades específicas das ocupações, a conquista de escolas nos acampamentos e a capacitação de professores até à construção de um modelo alternativo de educação radicalmente popular, e à erradicação do analfabetismo nas áreas de atuação. Já o setor de "Formação" abarca, de forma mais específica, a estruturação e organização dos cursos de formação política, como também se pode ler no site do MST:

A Escola Nacional Florestan Fernandes (ENFF) é um espaço destinado, por excelência, para a formação política de trabalhadores sem-terra precarizados que passam a compor as fileiras do MST., por isso foi escolhida como objeto de pesquisa sociológica neste projeto. A inspiração pedagógica do movimento, que se cristaliza na ENFF, baseia-se em diversos autores e perspectivas de educação popular, mas como aponta Ribeiro (2015), sua principal fonte remete à chamada "educação libertadora", com base nas obras, metodologia e atuação do educador brasileiro Paulo Freire.

O MST considera de fundamental importância absorver trabalhadores rurais precarizados e oferecer-Ihes formação política para que se integrem à corrente de militantes do movimento. A Escola Nacional Florestan Fernandes torna-se assim o espaço principal em que o MST estrutura cursos de formação política sólida para esses trabalhadores, recebendo colaborações nos cursos de diversos intelectuais, professores, artistas e ativistas que são próximos do movimento.

O Movimento dos Trabalhadores Sem-Teto (MTST) surge no final dos anos 1990 das fileiras do próprio MST. O movimento se vê então na necessidade de articular um movimento específico para as questões políticas dos trabalhadores urbanos. A ocupação de terras (em muitos casos já terras urbanas) continua sendo de extrema importância para a formação política de trabalhadores precarizados recém incorporados pelo movimento.

Goulart (2011) aponta que o Movimento dos Trabalhadores Rurais Sem-Terra, o MST, passava a se preocupar também com a formação política e organização 
dos trabalhadores "das cidades" e não apenas "nas cidades". A partir da Marcha Nacional do MST em 1997, o movimento liberou militantes para construírem um movimento análogo nas cidades, a fim de enfrentar as consequências do neoliberalismo no mundo urbano, naquele momento notadamente o desemprego, a precarização do trabalho e a falta de acesso à moradia. O MTST vai aos poucos se estruturando, tendo a organização de trabalhadores precarizados como uma de suas propostas centrais, ressaltando as dificuldades da organização sindical e a importância da organização política a partir do "território". O movimento atua politicamente em diversas questões relacionadas à classe trabalhadora nas cidades. Não se define simplesmente como mais um "movimento de moradia", ainda que a moradia faça parte dos direitos necessários para a população mais pobre viver nas cidades. De forma geral, o setor da classe trabalhadora que se incorpora ao MTST nas ocupações vive uma realidade de precarização do trabalho, dificuldade em pagar aluguéis, desemprego, miséria ou pobreza, e faz-se necessário enfrentar e superar também esses problemas.

O aumento do desemprego, atrelado a uma forte competição entre os trabalhadores, engendrou uma situação em que a "empresa neoliberal" tinha muito mais facilidade para desestruturar os grandes e antigos coletivos de trabalho. Como exemplo pode-se citar a questão das terceirizações, que logrou dispersar as concentrações de trabalhadores nas fábricas e facilitar a destruição das "antigas relações políticas", empurrando grande parte da "nova classe trabalhadora" para o setor de serviços, carente de organizações coletivas consolidadas e fortalecidas. Além disso, outro fator merece destaque na reconfiguração e na construção de novos espaços de trabalho nos anos 1990: "[...] uma concepção reestruturada do espaço e com fartura de equipamentos informacionais, permitiu uma profunda transformação da organização do trabalho à qual nem todos os integrantes da "velha classe trabalhadora" puderam adaptar-se" (BRAGA, 2006, p. 138).

O MTST desenvolve formas diversas de formação política. A ocupação de terras, assim como ocorre com o MST tem para o movimento um caráter pedagógico e formativo por excelência. É o primeiro momento de aprendizado e formação na própria ação política direta. Mas é inegável o potencial do movimento em organizar e formar politicamente trabalhadores precarizados nos últimos anos. Em sua organização interna, o MTST, assim como o MST, também conta com um "setor de formação". O MTST não conta com uma estrutura tal qual o MST, que por exemplo tem a Escola Nacional Florestan Fernandes como principal centro de formação. Também não tem ainda uma rede de relações com outros movimentos sociais, universidades, partidos políticos de esquerda, frentes amplas de 
mobilização que lhe permitam oferecer cursos de formação política estruturados como os do MTST. Mas, desde suas origens, o movimento reserva lugar especial para a formação de seus militantes e realiza essa formação, progressivamente, em suas ocupações. Tem sido cada vez mais comum o MTST fazer parcerias com grupos locais de educação popular e de teatro, a fim de que participem da formação política de seus militantes a partir de seus territórios (GOULART, 2011).

As transformações sociais no meio rural têm se mostrado socialmente excludentes nas últimas décadas, relacionadas a um avanço tecnológico cada vez maior na produção e à precarização do emprego nas relações de trabalho, caracterizadas pelo autoritarismo e pela informalidade. No Brasil, desde a década de 1960 há uma efetiva diminuição do trabalho permanente no campo, relacionada a enormes taxas de êxodo rural, ao crescimento do trabalho sazonal e ao aumento dos contratos informais de trabalho (GONÇALO, 2001).

No início da década de 1980 o mercado de trabalho no meio rural sofreu profundas alterações. Como reflexo do chamado "milagre econômico brasileiro" (1967-1972), a produção rural se viu cada vez mais refém do capitalismo urbano brasileiro. A produção no campo, principalmente a agricultura, assiste também a um crescimento da produtividade e a uma alta especialização do trabalho. E assim como o crescimento industrial, que puxou o "milagre econômico", o crescimento econômico no campo não significou mudanças positivas para os trabalhadores rurais. Destarte conquistas pontuais, a propriedade da terra continuou extremamente concentrada e os direitos sociais avançaram pouco (SILVA, 2007).

Nas últimas décadas o capital industrial e comercial operou profundas transformações na estrutura social do campo no Brasil. Um considerável contingente de pequenos produtores se viu obrigado a deixar de produzir para a subsistência e para mercados locais e a se inserir na dinâmica do mercado capitalista globalizado. Para tanto, a maioria dos pequenos produtores ficam reféns de insumos e tecnologias de propriedade de grandes corporações, os quais se veem na necessidade de adquirir. Sem conseguir competir no mercado com essas mesmas grandes corporações, muitos pequenos produtores têm que complementar sua renda familiar com trabalhos temporários e sazonais, o que aumenta o grau de precarização do trabalho no campo (GONÇALO, 2001).

Esse contingente de pequenos produtores, que se tornam pauperizados mesmo em jornadas duplas, também tem dificuldade de acesso a direitos e políticas sociais. Como aponta Gonçalo (2001, p. 13): "Há aproximadamente sete 
milhões de assalariados rurais no Brasil, de um total de catorze milhões de pessoas ocupadas na agricultura (...), cerca de cinco milhões de assalariados rurais não possuem carteira assinada nem direitos trabalhistas como $13^{\circ}$ salário, férias e FGTS". Pode-se afirmar, assim, que o trabalho no campo, a despeito de incontáveis avanços tecnológicos, segue uma tendência de precarização cada vez mais intensa no país.

Como aponta Schlindwein (2011), os trabalhadores rurais passam a integrar o conjunto das ações de proteção social no Brasil somente na década de 1970, diferentemente do trabalhador urbano, que passou a ter alguns direitos assegurados a partir da década de 1930. E ainda assim, com disparidades enormes entre as duas categorias, o que fica evidente, por exemplo, nas questões que tocam à aposentadoria e aos acidentes de trabalho, as quais o trabalhador rural tem ínfima proteção social ainda hoje.

Ainda segundo Schlindwein (2011), a Constituição de 1988 pode ser considerada um marco na história da luta por direitos dos trabalhadores rurais no Brasil. Principalmente as conquistas no acesso aos benefícios previdenciários foram frutos de intensa mobilização social de entidades como a Confederação Nacional dos Trabalhadores na Agricultura (CONTAG), a Federação dos Trabalhadores na Agricultura (FENTAG), os Sindicatos dos Trabalhadores Rurais (STRs), o Movimento das Mulheres Trabalhadoras Rurais (MMTR) e outros movimentos de representação e mobilização política que ganharam força nos anos 1980. Outras leis, como a que trata da aposentadoria de mulheres trabalhadoras rurais, por exemplo, só vieram na década de 1990. Ainda assim os direitos assegurados na Constituição de 1988 significaram um importante arcabouço no que toca à seguridade social para os trabalhadores rurais, em um momento em que o neoliberalismo impactaria fortemente o emprego e as relações de trabalho no país.

Sant'Ana (2014, p.5) aponta que desde a década de 1990 o chamado "agronegócio" vem se estruturando e se fortalecendo no cenário agrícola brasileiro: "(...) com presença massiva de capitais internacionais, aportes vindos dos governos e fortalecimento político de seus representantes". Ao passo que o agronegócio foi se fortalecendo nas últimas duas décadas, as políticas de seguridade social foram regredindo. As taxas de êxodo rural continuaram aumentando, bem como o desemprego no campo. Mudanças significativas na estrutura fundiária do país em prol dos trabalhadores são impossíveis no contexto neoliberal: 


\begin{abstract}
A agricultura familiar e a camponesa permanecem com menores investimentos e resistindo à pressão do modelo hegemônico, que produz tecnologia voltada para a monocultura e inflaciona o mercado de terras, de maneira a dificultar uma reforma agrária ampla e maciça e uma política agrícola de bases agroecológicas. Os rebatimentos desse processo sobre o mundo do trabalho são evidentes: a desertificação do campo em áreas de monocultura, a diminuição dos agricultores familiares e camponeses, a precarização do trabalho assalariado, a concentração dos maiores índices de pobreza em área rural e o acirramento da luta pela terra. (SANT'ANA, 2014, p. 6)
\end{abstract}

Esse modelo agrário monocultor e exportador remonta aos projetos de "modernização do campo" capitaneados pela ditadura civil-militar brasileira (19641985) no final dos anos 1970 e início dos anos 1980. Já nesse período a resistência a esse modelo começa também a se articular. Em janeiro de 1984 realiza-se na cidade de Cascavel, estado do Paraná, um grande encontro de trabalhadores rurais, no qual se decide pela construção do Movimento dos Trabalhadores Rurais Sem-Terra, o MST. Em janeiro de 1985 realiza-se na mesma cidade $01^{\circ}$ Congresso Nacional do MST. O movimento viria a se constituir como 0 maior movimento social do país nos anos seguintes e teria um papel decisivo na incorporação de trabalhadores rurais precarizados e na formação política desse contingente, do qual grande parte viria a se tornar militante política ativa do movimento.

A pesquisa teve também o objetivo de analisar a estrutura, o conteúdo e as práticas formativas do MST nos cursos oferecidos na Escola Nacional Florestan Fernandes (ENFF), principal espaço de formação do MST, que tratam da atual crise estrutural do capital, principalmente no que incide diretamente na precarização do trabalho rural. Morissawa (2007) aponta que o MST tem, desde suas origens, uma atenção especial para os espaços formativos em sua dinâmica de atuação. Após as primeiras ocupações de terra do movimento na década de 1980 e como fruto, principalmente, de seu 1ํㅡㄹ Congresso Nacional, o MST já defendia que as ocupações têm um caráter pedagógico por excelência. Quem nelas está envolvido aprende, ensina e partilha conhecimentos. Mas já reconhecia que para manter a dinâmica e os propósitos do movimento coesos seriam necessários espaços específicos de formação política.

Hoje o MST conta com onze setores em sua estrutura de organização, sendo um deles de "Educação" e outro de "Formação". O setor de "Educação", que atua 
constantemente nos acampamentos e assentamentos, abarca uma perspectiva ampla, que envolve desde as necessidades específicas das ocupações, a conquista de escolas nos acampamentos e a capacitação de professores até à construção de um modelo alternativo de educação radicalmente popular, e à erradicação do analfabetismo nas áreas de atuação. Como é explicitado no site do movimento:

\footnotetext{
Se a terra representa a possibilidade de trabalhar, produzir e viver dignamente, a educação é o outro instrumento fundamental para a continuidade da luta. Com isso, o Setor de Educação busca dar repostas às necessidades educacionais nos acampamentos e assentamentos. Os maiores objetivos são a erradicação do analfabetismo nas áreas, a conquista de condições reais para que toda criança e adolescente esteja na escola, isso implica na luta por escolas de ensino fundamental e médio dentro dos assentamentos, a capacitação dos professores para que sejam respeitados enquanto sabedores das necessidades e portadores da novidade de construir uma proposta alternativa de educação popular (MST, s/d).
}

Além dos setores organizativos há um espaço destinado aos editoriais do movimento, no qual um dos eixos é "Educação, Cultura e Comunicação". Esse eixo, que atua na edição dos jornais e nos materiais pedagógicos do MST, tem uma concepção de educação e formação política com base no Dicionário na Educação do Campo, o qual tem a seguinte definição: "A educação e o acesso à cultura, ao conhecimento, a valorização dos saberes populares, é condição fundamental para a realização dos brasileiros como seres humanos plenos, com dignidade e altivez." (CALDART et al. 2012, p. 239).

A ENFF está situada no município paulista de Guararema e foi inaugurada com um grande evento internacional em 23 de janeiro de 2005. Construída entre os anos de 2000 e 2005, a partir do trabalho voluntário de mais de mil trabalhadores semterra e simpatizantes, hoje a escola oferece grande quantidade de cursos em várias áreas do conhecimento. A Associação dos Amigos da Escola Nacional Florestan Fernandes (AAENFF), entidade de militantes e colaboradores, que objetiva divulgar atividades, desenvolver parcerias, promover campanhas de solidariedade e de arrecadação de recursos, assim define a escola:

Sua missão é a de atender às necessidades da formação de militantes de movimentos sociais e organizações que lutam por um 


\begin{abstract}
mundo mais justo (...) Atualmente a ENFF encontra-se ameaçada pelo estrangulamento econômico, no contexto da ofensiva orquestrada pela direita brasileira contra os movimentos sociais, particularmente o MST. No momento em que os movimentos sociais são obrigados a mobilizar suas energias para resistir aos ataques dos donos do capital, a Escola também se torna alvo dessa política: as classes dominantes não aceitam a ideia de que os trabalhadores se tornem sujeitos conscientes de sua própria história (ENFF, s/d.a).
\end{abstract}

\title{
METODOLOGIA
}

A metodologia da pesquisa consistiu em levantamento bibliográfico que servirá de referência nos temas apontados na apresentação do texto. A parte teórica dialogou com a pesquisa de campo criando uma síntese no momento da sistematização e redação; e também fundamentou a própria pesquisa de campo nos objetivos e hipóteses a que ela se propôs, conforme aponta Demo (1987) e os estudos de caso de Antunes (2011) e Braga (2006). Na pesquisa de campo foram realizadas entrevistas semiestruturadas com os trabalhadores que frequentam os cursos do MST na ENFF e nas ocupações do MTST na região metropolitana de São Paulo, a fim de traçar um perfil desses trabalhadores quanto às suas trajetórias ocupacionais e quanto ao seu interesse em compor os movimentos sociais em questão como militantes políticos.

\section{RESULTADOS E DISCUSSÃO}

A Escola Nacional Florestan Fernandes (ENFF) é um espaço destinado, por excelência, para a formação política de trabalhadores sem-terra precarizados que passam a compor as fileiras do MST., por isso foi escolhida como objeto de pesquisa sociológica neste projeto. A inspiração pedagógica do movimento, que se cristaliza na ENFF, baseia-se em diversos autores e perspectivas de educação popular, mas como aponta Ribeiro (2015), sua principal fonte remete à chamada "educação libertadora", com base nas obras, metodologia e atuação do educador brasileiro Paulo Freire. Esta perspectiva de educação, desde 1961 com o Movimento de Educação de Base (MEB), passou a defender que o projeto educacional e pedagógico do campo político da classe trabalhadora não poderia ser o mesmo projeto educacional e pedagógico do campo político do capital. Com 
inspiração no espectro teórico do marxismo, os educadores populares do MEB começavam a perceber que o projeto educacional dos setores oprimidos da sociedade estava intrinsecamente ligado a um projeto político próprio. O projeto da classe trabalhadora, da educação de caráter libertador, deveria estar, então, atrelado à luta de classes. No caso da classe trabalhadora precarizada do campo, deveria estar atrelada ao enfrentamento ao latifúndio e à luta pela reforma agrária (RIBEIRO, 2015).

O primeiro momento em que se torna claro que o enfrentamento de interesses de classe ocorre é na própria ocupação de terras. Segundo Silva (2007), a ocupação é um momento de disputa, contestação e ruptura da propriedade privada, o que vislumbra e fomenta a construção de uma nova ordem social. A expropriação de terras sugere um campo amplo para debates, compreensão e aprofundamento da consciência em torno do controle e do domínio que existe no bojo da sociedade capitalista. Ela define a expropriação como "[...] processo complexo e interligado entre produção material e ideológica da vida, a partir da caracterização da expropriação dos meios de produção, compreendemos o caráter educativo que a sustenta, ao mesmo tempo em que é gerado por ela." (SILVA, 2007, p. 7).

Posteriormente, esse conhecimento advindo da prática política é sistematizado para os cursos de formação na ENFF. Os cursos na escola expressam a leitura e a interpretação que o MST faz da presente crise do capital e da precarização do trabalho no campo. O movimento compartilha nos cursos a tese de Mészaros (2002) ao defender que esta crise é a manifestação das consequências mais perniciosas da ordem regida pelo capital, que afeta primordialmente os trabalhadores e também ecossistemas inteiros. Os principais sintomas da crise são o desemprego estrutural, a precarização intensiva da força de trabalho e a catastrófica e intensa destruição ambiental. Com base em estudo de Pinassi (2009) o MST também defende a tese de que, durante sua fase de ascensão histórica, o sistema metabólico do capital protelava a agudização de problemas como a precarização do trabalho, utilizando-se de sua estrutura hierárquica e sedimentada no desenvolvimento desigual, transferindo suas contradições do centro para a periferia do sistema.

Ainda segundo Pinassi (2009), em um determinado momento de acumulação, os limites absolutos do capital são desafiados, a crise se manifesta em quatro eixos principais e de forma estrutural: possui caráter universal no mundo do trabalho, seu caráter estrutural afeta todas as economias nacionais, atinge uma escala temporal 
permanente e, por fim, tem um caráter "sub-reptício", rastejante, diferente das bruscas alterações do sistema nos séculos XIX e XX. É uma crise que afeta a totalidade do sistema, precarizando o trabalho, recaindo nos setores oprimidos social, política e economicamente, além de causar impactos ambientais irreversíveis. (MÉSZAROS, 2002).

Vê-se que o MST considera de fundamental importância absorver trabalhadores rurais precarizados e oferecer-lhes formação política para que se integrem à corrente de militantes do movimento. A Escola Nacional Florestan Fernandes torna-se assim o espaço principal em que o MST estrutura cursos de formação política sólida para esses trabalhadores, recebendo colaborações nos cursos de diversos intelectuais, professores, artistas e ativistas que são próximos do movimento. É importante se destacar que com as reconfigurações da dinâmica rural-urbano no Brasil, o movimento tem sido responsável também por absorver e formar politicamente na ENFF muitos trabalhadores urbanos, sejam trabalhadores precarizados que sempre se ocuparam na cidade, sejam trabalhadores provenientes da zona rural, mas que desempenham frequentemente trabalhos sazonais nas regiões urbanas (MARTINS, 2004)

O Movimento dos Trabalhadores Sem-Teto (MTST) surge no final dos anos 1990 das fileiras do próprio MST. O movimento se vê então na necessidade de articular um movimento específico para as questões políticas dos trabalhadores urbanos. A ocupação de terras (em muitos casos já terras urbanas) continua sendo de extrema importância para a formação política de trabalhadores precarizados recémincorporados pelo movimento. O MTST é confrontado com três aspectos da conjuntura neoliberal brasileira, que impõem reformulações em relação ao MST para a atuação do movimento a partir dos anos 2000. Como aponta Goulart (2011, p.3):

[...] a mudança da base social dos movimentos sociais que sofre com a intensa precarização do trabalho, com o crescimento do desemprego estrutural e não tem qualquer experiência em organizações de trabalhadores. Em segundo, a aplicação de políticas sociais regressivas pelos governos neoliberais desde os anos 1990, a piora das condições gerais de vida da classe trabalhadora, que por outro lado, se vê apartada de sua direção histórica, o PT e a CUT, que ao longo dos anos 90, aderiram ao neoliberalismo até completar este ciclo com a vitória eleitoral em 2002, que elege Lula para a Presidência da República. 
O MTST cresce em número de ocupações nos anos seguintes à sua fundação e chega à nacionalização em 2009. Mas desde o final dos anos 1970, os movimentos sociais urbanos já despontavam como resposta à chamada "crise urbana", que implicava em altas taxas de desemprego nas regiões metropolitanas, precarização do trabalho e carência de moradias (MARICATO, 2015). A conjuntura neoliberal em que o movimento foi forjado impôs novas formas de enfrentamento do movimento com o Estado e com o capital, o que fez com que o MTST assumisse uma postura nitidamente anticapitalista e radicalizada na luta por direitos da classe trabalhadora urbana no Brasil.

O MTST faz referência à sua origem em um documento, a Cartilha do Militante de 2005, onde confere ao MST um papel de coautor em sua formação e formula uma explicação para sua atuação na cidade. Goulart (2011) aponta que o Movimento dos Trabalhadores Rurais Sem-Terra, o MST, passava a se preocupar também com a formação política e organização dos trabalhadores "das cidades" e não apenas "nas cidades". A partir da Marcha Nacional do MST em 1997, o movimento liberou militantes para construírem um movimento análogo nas cidades, a fim de enfrentar as consequências do neoliberalismo no mundo urbano, naquele momento notadamente o desemprego, a precarização do trabalho e a falta de acesso à moradia. Foi na cidade de Campinas-SP que o MTST lançou suas bases de construção autônoma com a ocupação "Parque Oziel" em fevereiro de 1997.

As dificuldades eram novas para os trabalhadores precarizados que participaram da ocupação e também para militantes do MST que não estavam acostumados com a complexidade das relações nas grandes cidades, como, por exemplo: "[...] o papel das forças políticas dentro da cidade, como se organizar nesse meio, como se relacionar com os partidos políticos, com o tráfico de drogas e com todas as facções que se organizam no meio urbano" (BENOIT, 2002, p. 141). E essa complexa realidade urbana viria a se apresentar duramente para o movimento em outras ocupações pelo estado de São Paulo ainda no ano de 1997, justamente em um momento em que o governo de Fernando Henrique Cardoso (1995-2002) criminalizava diversos movimentos sociais e em que o crime organizado crescia exponencialmente nas periferias urbanas.

O MTST vai aos poucos se estruturando, tendo a organização de trabalhadores precarizados como uma de suas propostas centrais, ressaltando as dificuldades da organização sindical e a importância da organização política a partir do "território" em que o setor da classe trabalhadora precarizada vive no atual 
contexto social. O movimento atua politicamente em diversas questões relacionadas à classe trabalhadora nas cidades. Não se define simplesmente como mais um "movimento de moradia", ainda que a moradia faça parte dos direitos necessários para a população mais pobre viver nas cidades. De forma geral, o setor da classe trabalhadora que se incorpora ao MTST nas ocupações vive uma realidade de precarização do trabalho, dificuldade em pagar aluguéis, desemprego, miséria ou pobreza, e faz-se necessário enfrentar e superar também esses problemas. Além disso, muitos bairros periféricos urbanos enfrentam diversas dificuldades infraestruturais, como falta de escolas, postos de saúde, transporte coletivo, segurança, áreas de cultura e lazer, coleta de lixo e esgoto e outros. O MTST atua constantemente, junto às populações locais, para enfrentar também essas demandas junto ao poder público e à sociedade de forma geral. O MTST defende uma Reforma Urbana estrutural como forma de resolver o conjunto desses problemas e postula ideais de transformação mais ampla da sociedade. O MTST tem lidado nesses anos desde sua fundação com uma classe trabalhadora cada vez mais precarizada e carente de direitos sociais. Segundo Braga (2006, p.137), foi na década de 1990 que um novo regime de acumulação mais ou menos coerente conseguiu se estruturar:

\footnotetext{
Assistimos então à desestruturação da empresa fordista em benefício de um modelo de organização das relações de produção orientado pela generalização do processo de terceirização, pela compressão dos níveis hierárquicos, pelo desenvolvimento de estratégias gerenciais objetivando a mobilização permanente da força de trabalho, pela cooperação constrangida dos assalariados, pela administração por metas, assim como pela fragmentação da relação salarial.
}

O aumento do desemprego, atrelado a uma forte competição entre os trabalhadores, engendrou uma situação em que a "empresa neoliberal" tinha muito mais facilidade para desestruturar os grandes e antigos coletivos de trabalho. Como exemplo pode-se citar a questão das terceirizações, que logrou dispersar as concentrações de trabalhadores nas fábricas e facilitar a destruição das "antigas relações políticas", empurrando grande parte da "nova classe trabalhadora" para o setor de serviços, carente de organizações coletivas consolidadas e fortalecidas. Além disso, outro fator merece destaque na reconfiguração e na construção de novos espaços de trabalho nos anos 1990: "[...] uma concepção reestruturada do 
espaço e com fartura de equipamentos informacionais, permitiu uma profunda transformação da organização do trabalho à qual nem todos os integrantes da "velha classe trabalhadora" puderam adaptar-se" (BRAGA, 2006, p. 138).

Maricato (2015) aponta que a exploração da força de trabalho nas cidades tem se dado em um contexto no qual a estrutura mesma das cidades "dificultam", paradoxalmente para o capital, a reprodução da força de trabalho. Um trabalhador que demora para se deslocar ao local de trabalho, devido às grandes distâncias e à precariedade dos meios de transporte, gasta grande parte de seu "tempo livre" com afazeres como compras para a casa, cuidados com a saúde, vivência familiar etc. e dorme cada vez menos, tende a não permanecer muito tempo em uma mesma empresa, o que aumenta a rotatividade do trabalho de forma geral e a dificuldade para se aposentar, visto que grande parte da classe trabalhadora urbana passa também um tempo considerável de seu tempo de trabalho na informalidade, sem contribuir para a previdência social. Para resolver esse "paradoxo" o capital, atrelado a um processo crescente de urbanização, estimula o crescimento populacional da classe trabalhadora precarizada, desde os anos 1960, a fim de aumentar o "exército industrial de reserva" e manter um controle maior sobre a força de trabalho (Idem).

Para Antunes (2011), a recente crise estrutural do capital, que eclodiu em 2008 nas economias centrais, fez ampliar significativamente a precarização do trabalho e corroeu ainda mais o trabalho contratado e regulamentado, gerando novas formas de precarização e informalidade. Nos últimos anos, pode-se considerar que há uma precarização estrutural do trabalho (ANTUNES, 2011; CARVALHO, 2014). Nesse contexto, o fluxo global de capitais exige o desmonte das legislações trabalhistas nacionais, o que significa o aumento dos mecanismos de exploração do trabalho e a destruição de direitos sociais que foram conquistados desde a Revolução Industrial nas economias centrais e desde a década de 1930 no Brasil (Idem).

No que toca aos direitos sociais, o retrocesso é cada vez maior nos dias atuais. Antunes (2011) aponta que as reformas em curso no Brasil são um cenário de "devastação" nos direitos conquistados a duras penas: "Este pacote da reforma trabalhista, por exemplo, junto com a proposta de destroçamento da previdência, acaba mostrando que o governo [...] se agarra no colo das classes dominantes para fazer tudo o que essas classes não estavam conseguindo fazer na intensidade que queriam." (ANTUNES, 2011). 
O MTST lida, assim, em um contexto extremamente difícil para a organização e formação política da classe trabalhadora urbana. Mas, dialeticamente, esse mesmo contexto cria novas possibilidades para a absorção e formação de novos militantes do movimento. O movimento tem uma organização interna que explicita a sua preocupação com a formação de trabalhadores precarizados. O MTST tem uma reflexão sobre a base social de trabalhadores que compõe o movimento e, a partir dessa reflexão, estrutura momentos formativos nas ocupações, à semelhança do MST. O próprio movimento define em seu site a análise que faz do setor da classe trabalhadora junto ao qual atua: "[...] o capital dividiu os trabalhadores devido à diversificação das formas de trabalho: relação assalariada e trabalho por conta própria; formalidade e informalidade; contratos temporários; terceirização; desemprego crônico, etc." (MTST s/d). E também faz uma projeção de suas ações políticas, classificando-se como um "[...] movimento popular, que tem como elemento central a classe trabalhadora, e que expressa sua luta por direitos negados pelo capital e pelo Estado, tais como terra, moradia, serviços básicos etc. ou por resistência às opressões sofridas enquanto classe" (MTST s/d).

A partir dessa reflexão o MTST projeta sua organização interna e também seus objetivos de organização política. Com a diminuição da base de influência dos sindicatos, que atuam unicamente entre os trabalhadores em sua base profissional, grande parte da classe trabalhadora precarizada é fragmentada e não dispõe de elementos coletivos de organização (BRAGA, 2006). Grande parte desses trabalhadores são atraídos por ações assistencialistas conservadoras de governos e ONGs ou acabam se inserindo em organizações criminosas, abdicando de uma inserção política efetiva, ainda que continuem sendo um "ator social" extremamente importante na atual configuração da classe trabalhadora urbana. Goulart (2011) destaca que a fragmentação desse setor de trabalhadores gera uma formação política descontinuada e dificulta a formação de uma base social consistente e organizada no MTST. É um problema que o movimento tem que lidar a todo o tempo.

\section{CONCLUSÃO}

O MTST, assim, desenvolve formas diversas de formação política. A ocupação de terras, assim como ocorre com o MST tem para o movimento um caráter pedagógico e formativo por excelência. É o primeiro momento de aprendizado e formação na própria ação política direta: 


\begin{abstract}
Nossa forma de ação mais importante são as ocupações de terras urbanas. Com elas pressionamos diretamente os proprietários e 0 Estado, denunciamos o problema social da moradia e construímos um processo de organização autônoma dos trabalhadores. As ocupações são sempre acompanhadas de uma pressão focada nos órgãos do Estado, com marchas e ocupações de prédios públicos [...] entendemos também que as ocupações de terrenos nas periferias devem ser potencializadas como uma porta para o trabalho comunitário nos bairros próximos. Não podem ser uma ilha de lutadores; mas devem avançar para uma integração com as demandas dos trabalhadores que não participam diretamente dos acampamentos, ampliando nossa referência. (MTST, s/d)
\end{abstract}

Mas é inegável o potencial do movimento em organizar e formar politicamente trabalhadores precarizados nos últimos anos. _No Relatório da Reunião Nacional do MTST de 2009, o capitalismo é definido como um sistema de "natureza contraditória e opressora que impede o acesso da maioria da população ao poder e às riquezas sociais" (2009, p.13). Em sua organização interna, o MTST, assim como o MST, também conta com um "setor de formação". O MTST não conta com uma estrutura tal qual o MST, que por exemplo tem a Escola Nacional Florestan Fernandes como principal centro de formação. Também não tem ainda uma rede de relações com outros movimentos sociais, universidades, partidos políticos de esquerda, frentes amplas de mobilização que lhe permitam oferecer cursos de formação política estruturados como os do MTST. Mas, desde suas origens, o movimento reserva lugar especial para a formação de seus militantes e realiza essa formação, progressivamente, em suas ocupações. Tem sido cada vez mais comum o MTST fazer parcerias com grupos locais de educação popular e de teatro, a fim de que participem da formação política de seus militantes a partir de seus territórios (GOULART, 2011)

Por isso, também foi objetivo dessa pesquisa analisar como o MTST estrutura e oferece momentos de formação política, em suas ocupações, para setores precarizados da classe trabalhadora recém incorporados ao movimento. Por fim, pretendeu-se comparar a estratégia dos dois movimentos na incorporação de setores precarizados da classe trabalhadora rural e urbana. A partir da análise dos setores que são incorporados pelos movimentos e pela estrutura e dinâmica da formação política oferecida pelos movimentos a esses setores, procurou-se- traçar um panorama atual de setores da classe trabalhadora precarizada, que são incorporados por dois dos maiores movimentos sociais do país, passam por um 
processo de formação política e se tornam militantes políticos orgânicos dos

movimentos.

\section{REFERÊNCIAS}

ANTUNES, R. "Os modos de ser da informalidade: rumo a uma nova era da precarização estrutural do trabalho?", Serv. Soc. Soc., São Paulo, n. 107, p. 405-419, jul./set. 2011.

BENEDICTO, S.; ROMANIELLO, M.; ASILVA, A.; STIEG, C. "Precarização das relações do trabalho rural no Brasil: uma abordagem histórico-analítica". I Encontro de Gestão de Pessoas e Relações de Trabalho, Natal, 2007.

BENOIT, H. "O assentamento Anita Garibaldi: entrevista com lideranças do Movimento dos Trabalhadores Sem Teto (MTST"). Revista Crítica Marxista. São Paulo, n.14, p. 134-149, 2002.

BRAGA, R. "Uma sociologia da condição proletária", Tempo Social, revista de sociologia da USP, v. 18, n. 1, p133-152, 2006.

BURAWOY, M. Marxismo Sociológico, Rio de Janeiro, Alameda Editorial, 2014.

CALDART, T.; PEREIRA, I.; ALENTEJANO, P.; FRIGOTTO, G. (Orgs.), Dicionário da educação do campo, São Paulo: Expressão Popular, 2012.

CARTILHA DO MILITANTE DO MTST (2005), disponível em ww.mtst.org.br, acesso em 22/05/2017.

CARVALHO, A. "A precarização estrutural do trabalho na civilização do capital em crise: o precariado como enigma contemporâneo", R. Pol. Públ., São Luís, Número Especial, p. 225239, 2014.

DEMO, Metodologia científica em Ciências Sociais, São Paulo: Editora Atlas, 1987.

ENFF. (s/d.b), Formação. Disponível: em <http://www.amigosenff.org.br/ptBR/aescola/formacao.> Acesso em: 15 mai.2015.

GONÇALO, J. Reforma agrária como política social redistributiva. Brasília: Editora Plano, 2001.

GOULART, D. O anticapitalismo do Movimento dos Trabalhadores Sem-Teto (MTST), Tese (doutorado) - Universidade Estadual Paulista, Faculdade de Filosofia e Ciências, 2011.

MARICATO, E. Para entender a crise urbana, São Paulo: Expressão Popular, 2015.

MÉSZAROS, I. (2002), Para além do capital, São Paulo: Boitempo Editorial.

MORISSAWA, M. (2007), A luta pela terra e o MST, São Paulo: Expressão Popular.

MST. (s.d.) Quem somos. Disponível em: <http://www.mst.org.br/quem-somos/>. Acesso em: 15 mai. 2015.

PINASSI, M. Da miséria ideológica à crise do capital, São Paulo: Boitempo Editorial, 2009.

RIBEIRO, M. "Reforma agrária, trabalho agrícola e educação rural: desvelando conexões históricas da educação do campo", Educação e Pesquisa., São Paulo, v. 41, n. 1, p. 79-100, jan./mar. 2015.

SANTA'ANA, A. "Trabalho e Desenvolvimento: a realidade rural e a questão social", Serv. Soc. Soc. no.120 São Paulo Oct./Dec. 2014.

SCHLINDWEIN, M., "A desproteção social dos trabalhadores rurais nos acidentes de trabalho", Textos \& Contextos (Porto Alegre), v. 10, n. 1, p. 109 - 117, jan. /jul. 2011.

SILVA, G. "A Natureza Educativa das Ocupações de Luta Pela Terra no Brasil", Revista Libertas eletrônica, Pesquisado em 20/05/2017, Disponível em www.ufjf.br/revistalibertas/ 